\title{
Correction to: Operator decision support system for integrated wastewater management including wastewater treatment plants and receiving water bodies
}

\author{
Minsoo Kim ${ }^{1} \cdot$ Yejin $\mathrm{Kim}^{2} \cdot$ Hyosoo $\mathrm{Kim}^{3} \cdot$ Wenhua Piao ${ }^{1} \cdot$ Changwon Kim ${ }^{1}$
}

Published online: 31 May 2019

(C) Springer-Verlag GmbH Germany, part of Springer Nature 2019

Correction to: Environ Sci Pollut Res (2016) 23:10785-10798

https://doi.org/10.1007/s11356-016-6272-6

The original corresponding authorship was transferred from Changwon Kim to Yejin Kim by Changwon Kim's request. All the authors agreed to that.

Publisher's note Springer Nature remains neutral with regard to jurisdictional claims in published maps and institutional affiliations.

The online version of the original article can be found at https://oi.org/ $10.1007 / \mathrm{s} 11356-016-6272-6$

Yejin Kim

yjkim@cup.ac.kr

1 Department of Civil and Environmental Engineering, Pusan National University, Busan 609-735, Republic of Korea

2 Department of Environmental Engineering, Catholic University of Pusan, Busan 609-757, Republic of Korea

3 EnvironSoft Co., Ltd, Pusan National University, \#511

Industry-University Co., Bld., Busan 609-735, Republic of Korea 